\title{
Comparison between Radiofrequency Ablation and Sublobar Resections for the Therapy of Stage I Non-Small Cell Lung Cancer: A Meta-Analysis
}

\author{
Shuang Chen ${ }^{1}$, Shize Yang ${ }^{2}$, Shun $\mathrm{Xu}^{2}{ }^{2}$, Siyuan Dong ${ }^{\text {Corresp. } 2}$ \\ ${ }^{1}$ Department of Cardiovascular, The first hospital of China Medical University, Shenyang, China \\ 2 Department of Thoracic, The first hospital of China Medical University, Shenyang, China \\ Corresponding Author: Siyuan Dong \\ Email address: sydong@cmu.edu.cn
}

Background. Sublobar resection (SLR) and radiofrequency ablation (RFA) are the two minimally invasive procedures performed for treating stage I non-small cell lung cancer (NSCLC). This study aimed to compare SLR and RFA for the treatment of stage I NSCLC using the meta-analytical method. Methods. We searched PubMed and Embase for articles published till December 2019 to evaluate the comparative studies and assess the survival and progression-free survival rates and postoperative complications (PROSPERO registration number: 176765). A meta-analysis was performed by combining the outcomes of the reported incidences of short-term morbidity and long-term mortality. The fixed or random effects model was utilized to calculate the pooled odds ratios (OR) and the $95 \%$ confidence intervals. Results. Four retrospective studies were considered in the course of this study. The studies included a total of 309 participants; 154 were assigned to the SLR group, and 155 were assigned to the RFA group. Moreover, there were statistically significant differences between the one- and three-year survival rates and oneand three-year progression-free survival rates for the two groups, which were in favor of the SLR group. Among the post-surgical complications, pneumothorax and pleural effusion were more common for the SLR group, while cardiac abnormalities were prevalent in the RFA group. There was no difference in prevalence of hemoptysis between SLR and RFA groups, which might be attributed to the limited study sample size. Conclusion. Considering the higher survival rates and disease control in the evaluated cases, surgical resection is the preferred treatment method for stage I NSCLC. RFA can be considered a valid alternative in patients not eligible for surgery and in high-risk patients as it is less invasive and requires shorter hospital stay. 
1 Title: Comparison between Radiofrequency Ablation and Sublobar Resections for

2 the Therapy of Stage I Non-Small Cell Lung Cancer: A Meta-Analysis

4 Authors:

5 Shuang Chen ${ }^{1}$, Shize Yang ${ }^{2}$, Shun $\mathrm{Xu}^{2}$, Siyuan Dong ${ }^{2}$

$6{ }^{1}$ Department of Cardiovascular, The first hospital of China Medical University, Shenyang, China

$7 \quad 2$ Department of Thoracic, The first hospital of China Medical University, Shenyang, China

9 Corresponding author:

10 Siyuan Dong

11 Email: sydong@cmu.edu.cn 


\section{Abstract}

14 Background. Sublobar resection (SLR) and radiofrequency ablation (RFA) are the two minimally invasive procedures performed for treating stage I non-small cell lung cancer (NSCLC). This study aimed to compare SLR and RFA for the treatment of stage I NSCLC using the meta-analytical

17 method.

Methods. We searched PubMed and Embase for articles published till December 2019 to evaluate the comparative studies and assess the survival and progression-free survival rates and postoperative complications (PROSPERO registration number: 176765). A meta-analysis was

21 performed by combining the outcomes of the reported incidences of short-term morbidity and 22 long-term mortality. The fixed or random effects model was utilized to calculate the pooled odds 23 ratios (OR) and the $95 \%$ confidence intervals.

Results. Four retrospective studies were considered in the course of this study. The studies included a total of 309 participants; 154 were assigned to the SLR group, and 155 were assigned to the RFA group. Moreover, there were statistically significant differences between the one- and three-year survival rates and one- and three-year progression-free survival rates for the two groups, which were in favor of the SLR group. Among the post-surgical complications, pneumothorax and pleural effusion were more common for the SLR group, while cardiac abnormalities were prevalent in the RFA group. There was no difference in prevalence of hemoptysis between SLR and RFA groups, which might be attributed to the limited study sample size. 
32 Conclusion. Considering the higher survival rates and disease control in the evaluated cases,

33 surgical resection is the preferred treatment method for stage I NSCLC. RFA can be considered a

34 valid alternative in patients not eligible for surgery and in high-risk patients as it is less invasive

35 and requires shorter hospital stay. 
Introduction

39 Non-small cell lung cancer (NSCLC) continues to be the leading cause of death among all

40 malignant neoplasms, thus focusing the attention of scientists and physicians worldwide (Torre et

41 al. 2016). Considering the rapid development of science and technology, various diagnostic techniques, including low-dose computed tomography(CT) and positron emission tomographyCT, have been used to detect early-stage pulmonary malignancies (Menezes et al. 2010). The cornerstone of NSCLC therapy is surgical resection, and the "gold standard" surgical approach for stage I NSCLC is lobectomy with systematic mediastinal lymphadenectomy as it offers the best chance of cure (Howington et al. 2013). However, resection is possible in only $20 \%$ of patients diagnosed with stage I NSCLC. Patients who are candidates for lobectomy are often elderly and have a history of atherosclerotic cardiovascular disease, pulmonary dysfunction, or comorbidities related with cigarette smoking. Thus, less invasive modalities are preferred for the treatment of these patients, such as sublobar resection (SLR) (Harada et al. 2005), radiofrequency ablation

51 (RFA) (Kodama et al. 2014), and stereotactic body radiation therapy (Chang et al. 2015; Grills et al. 2010).

SLR, which is also referred to as 'limited resection,' is preferred for patients who cannot tolerate lobectomy with systematic mediastinal lymphadenectomy, as it preserves pulmonary function. SLR can be performed by anatomical segmentectomy or non-anatomical wedge resection, using open thoracotomy or applying video-assisted thoracoscopic surgery (VATS) approach. RFA is a minimally invasive approach using CT-guided percutaneous placement of an electrode into the 
lesion and generation of high-dose energy to cause coagulation necrosis (Ambrogi et al. 2011). Fernando's study (Fernando et al. 2004) presented RFA as the treatment choice for patients with stage I-II NSCLC, who are not eligible for surgery. In combination with other treatments, RFA can also be used to control a peripheral lesion in patients with advanced neoplasm (Hiraki et al. 2014).

For patients who are not eligible for lobectomy, SLR is recommended over non-surgical therapy (Donington et al. 2012). However, the superiority of SLR over RFA is still controversial (Kim et al. 2012; Zemlyak et al. 2010). Presently, there is no evidence from randomized controlled trials (RCTs) proving the RFA results better than SLR results in treating stage I NSCLC. This study aimed to evaluate the postoperative complications and survival rates of patients with stage I NSCLC, who underwent SLR or RFA.

\section{Materials \& Methods}

\section{Information sources and search strategy}

Our research was registered on PROSPERO (176765). Electronic searches were conducted by two investigators (Shuang Chen and Sheze Yang) using PubMed, Cochrane Library, Web of Science, Ovid MEDLINE, Google Scholar, and Embase databases until December 2019. The Medical Subject Heading terms and keywords included in our search strategy in a variety of combinations were "radiofrequency ablation," "sublobar resections," "non-small cell lung cancer," "stage I," "wedge resection," "segmentectomy," "RFA," and "SLR.” All related scientific original articles, reviews, animal studies, letters, opinion pieces, and editorials were researched. Only 
manuscripts written in English were considered. Moreover, the Science Citation Index was used to further cross-reference the studies which met the pre-defined inclusion criteria.

\section{Study selection}

Randomized intervention studies and observational cohort studies were eligible for inclusion if they followed-up patients for at least 3 years. Thus, the pre-defined inclusion criteria established for our research were as follows:

(1) Studies that compared the survival situation and postoperative complication rates of SLR and RFA in patients with stage I NSCLC;

(2) Articles documenting survival data from reports presented at major radiology and thoracic surgery academic conferences (RSNA, AATS, and EACTS) or studies that were published in peerreviewed publications;

(3) Studies comprising participants with similar main clinical characteristics and without a history of malignant tumors;

(4) Studies that reported at least one of the following results: survival, progression-free survival, and local recurrence rates (full texts were retrieved from studies that met all the inclusion criteria; SLR refers to wedge resection and segmentectomy);

The exclusion criteria were:

(1) Studies not comparing SLR or RFA as intervention methods and studies evaluating stages II, III, and IV NSCLC;

(2) Research focusing on participants' treatment for pulmonary metastases;

(3) Articles with overlapping information on researchers, hospitals, institutions, or participants' 
100

101

102

103

104

105

106

107

108

109

110

111

112

113

114

115

116

117

118

119

120

cohorts (only the most informative and newest literature was considered);

(4) Articles published in the past 20 years regarding recent remarkable technological advancements;

\section{Data extraction and quality assessment}

All the related studies were searched and reviewed by two independent investigators (Shuang Chen and Shize Yang) according to our pre-defined eligibility criteria. The investigators also extracted research data, study design, and baseline characteristics (age and sex) and endpoints according to the predesigned data extraction form. Any needed but incomplete survival information in the articles was acquired by directly contacting the author. Differences in data extraction results between the two investigators were solved through discussion between them and finally overseen by a third senior independent author (Siyuan Dong). The final extracted data were confirmed by two senior investigators (Siyuan Dong and Shun Xu). The selected studies were assessed for quality by applying the Downs and Black quality assessment method we had used in our previous studies (Dong et al. 2015; Dong et al. 2014; Downs \& Black 1998). The progressionfree survival was defined as the period from the date of the initial surgical resection or RFA until the date of recurrence.

\section{Data synthesis and statistical analysis}

Review Manager version 5.3 software package (Cochrane Collaboration Software) was utilized in this study. Survival data were reported as hazard ratios and dichotomous clinical outcomes as risk ratios. The corresponding 95\% confidence intervals (95\% CI) were calculated. Moreover, a p value $<0.05$ was considered statistically significant when assessing the value between SLR and 
121 RFA. A fixed-effects model was adapted if there was no statistically significant difference in terms 122 of heterogeneity ( $\mathrm{p}>0.05)$. Otherwise, a random-effect model was adopted. Heterogeneity between

123 all the included articles was investigated using the $I^{2}$ statistic with statistical significance $P<0.05$.

124 Hence, the upper thresholds for low, moderate, and high heterogeneity were defined as $I^{2}$ values 125 between $25 \%$ and $50 \%$, between $50 \%$ and $75 \%$, and greater than $75 \%$, respectively.

\section{Publication bias}

127 Visual inspection of funnel plots was applied to assess potential publication bias.

128

129

130

131

132

133

134

135

136

137

138

139

140

141

\section{Results}

\section{Study characteristics}

Four retrospective cohort studies that met our inclusion criteria were included in our study between 2010 and 2015: two from the USA and one each from Germany and Italy. A total of 309 participants were included in the research: 154 were assigned to the SLR group, and 155 were assigned to the RFA group to assess the postoperative complications and survival rates. As suggested by the Preferred Reporting Items for Systematic Reviews and Meta-Analyses statement (Liberati et al. 2009), we presented the process of identification and inclusion of studies in a flow diagram (Figure 1). The articles' evaluation index and basic characteristics and are presented in Table 1. Alexander's (Alexander et al. 2013), Ambrogi's (Ambrogi et al. 2015), and Safi's (Safi et al. 2015) research were in favor of SLR; however, in Zemlyak's (Zemlyak et al. 2010) study, RFA demonstrated a comparable effect to that of SLR in participants with stage I NSCLC.

\section{Assessment of complications}

These four studies compared the postoperative complications between the two groups. The 
142 postoperative complications included pneumothorax, hemoptysis, pleural effusion, and 143 postoperative cardiac abnormality. Two papers (Alexander et al. 2013; Zemlyak et al. 2010) 144 documented the results of hemoptysis $(\mathrm{OR}=0.32 ; 95 \% \mathrm{CI}, 0.03-3.17 ; p=0.33)$ with some 145 heterogeneity $\left(x^{2}=0.39, p=0.53, I^{2}=0 \%\right.$, Figure 2a). All four papers documented the results of 146 pneumothorax $(\mathrm{OR}=0.14 ; 95 \% \mathrm{CI}, 0.06-0.30 ; p<0.00001)$ with some heterogeneity $\left(\mathrm{x}^{2}=7.01\right.$, $147 \mathrm{p}=0.07, \mathrm{I}^{2}=57 \%$, Figure 2b). Three papers (Alexander et al. 2013; Ambrogi et al. 2015; Safi et al. 148 2015) documented the results of pleural effusion ( $\mathrm{OR}=0.24 ; 95 \% \mathrm{CI}, 0.06-0.98 ; p=0.05)$, with some heterogeneity $\left(\mathrm{x}^{2}=0.46, \mathrm{p}=0.80, \mathrm{I}^{2}=0 \%\right.$, Figure 2c). Three papers (Alexander et al. 2013; Ambrogi et al. 2015; Safi et al. 2015) documented the results of cardiac abnormality (OR=13.09; 95\% CI, 2.45-69.94; $p=0.003)$ with some heterogeneity $\left(\mathrm{x}^{2}=0.86, \mathrm{p}=0.65, \mathrm{I}^{2}=0 \%\right.$, Figure $\left.2 \mathrm{~d}\right)$.

Only postoperative cardiac abnormality was prevalent in the RFA group, and pneumothorax and pleural effusion were both prevalent in the SLR group. Hemoptysis incidence was the same for both groups.

\section{Assessment of survival and recurrence}

All four studies reported the results of the 1-year survival rate (Alexander et al. 2013; Ambrogi et al. 2015; Safi et al. 2015; Zemlyak et al. 2010), and no significant heterogeneity was observed among them $\left(\mathrm{x}^{2}=2.15, p=0.54, I^{2}=0 \%\right)$. Thus, a fixed-effects model was adopted $(\mathrm{OR}=3.34 ; 95 \%$ CI, 1.13-9.89; $p=0.03$, Figure $3 \mathbf{A}$ ). These four studies also reported the outcomes of the 3-year survival rate, and heterogeneity was calculated through the research $\left(\mathrm{x}^{2}=4.18, p=0.24, I^{2}=28 \%\right)$, using the fixed-effects model $(\mathrm{OR}=1.95 ; 95 \% \mathrm{CI}, 1.20-3.18 ; p=0.007$, Figure $3 \mathrm{~B})$. Only one 
$16335 \%$ for RFA); hence, the results could not be consolidated. All the results showed greater

164 prevalence in the SLR group.

165 Three articles (Ambrogi et al. 2015; Safi et al. 2015; Zemlyak et al. 2010) compared the 1-year

166 progression-free survival rate $(\mathrm{OR}=2.72 ; 95 \% \mathrm{CI}, 1.18-6.29 ; p=0.02)$, and no significant

167 heterogeneity among these articles was detected $\left(\mathrm{x}^{2}=0.34, p=0.84, I^{2}=0 \%\right.$, Figure 4 A). All three

168 studies also presented the 3 -year progression-free survival rate $(\mathrm{OR}=3.01 ; 95 \% \mathrm{CI}, 1.63-5.55$;

$169 p=0.0004)$; however, there was no significant heterogeneity among subjects treated with SLR and

170 those treated with RFA $\left(x^{2}=2.00, p=0.37, I^{2}=0 \%\right.$, Figure 4B). Nevertheless, significant 1 - and 3-

171 year progression-free survival rate benefits were observed in the SLR group. We also intended to

172 compare the 5-year progression-free survival rate results between the two groups. However, only

one article documented it, and it was in favor of SLR (Ambrogi et al. 2015). All the survival rate

results are presented in Table 2.

Considering that local recurrence is one of the most important aspects for evaluating the NSCLC

176

177

178

179

180

181

182

183

treatment efficacy, it was assessed in all four studies. There was no significant heterogeneity between these four studies $\left(x^{2}=3.11, p=0.38, I^{2}=3 \%\right)$, and the fixed-effects model was adopted.

The combined result was in favor of SLR (OR=0.18; 95\%CI, $0.10-0.35 ; p<0.00001$, Figure 4C).

We tried to consolidate the distant recurrence, but only one article in favor of SLR had documented it (Zemlyak et al. 2010). Hence, the available data was not suitable for further research.

\section{Publication bias}

Publication bias is possibly observed when non-significant outcomes remain unpublished, inevitably amplifying the evident magnitude of a function. This funnel plots of this study are 
demonstrated in Figure 5. The funnel plots of the 1-year survival rate following SLR and RFA for the treatment of stage I NSCLC manifested a slight asymmetry, and all points were within 95\% CI, suggesting a low publication bias.

\section{Discussion}

With the development of low-dose CT technology, early stage NSCLC can be immediately detected and diagnosed (Veronesi et al. 2008). Ever since the widely quoted research from the Lung Cancer Study Group was published in 1995, the standard treatment for patients with NSCLC has been lobectomy (Ginsberg \& Rubinstein 1995); however, some patients are at a high risk and refuse to undergo radical resection. Considering that only $20 \%$ of NSCLC patients are eligible for lobectomy, owing to complex clinical histories, some less invasive approaches are currently being developed, including RFA and SLR. These two approaches have shown promising results (Jones et al. 2015; Speicher et al. 2016).

RFA is a percutaneous treatment performed with local anesthesia and conscious sedation (Choe et al. 2009; Palussiere et al. 2015). Those highly in favor of RFA emphasize its definitive advantages over surgery, including outpatient treatment and the percutaneous performance of this procedure, using local anesthesia and avoiding thoracotomy for patients who refuse surgical resection or present severe comorbidities. RFA does not significantly affect the patient's cardiopulmonary function, and it is also associated with a significant decrease in the length of hospital stay. Moreover, RFA allows the ablation of lesions without major damage to the peripheral normal tissues (Simon et al. 2007; Wan et al. 2016a; Wan et al. 2016b). RFA complications are relatively minor and acute, although their frequency is considerable. Zemlyak's study (Zemlyak et al. 2010) 
205 showed that most patients undergoing RFA could be discharged within 24 hours of therapy, and

206 RFA has similar overall and cancer-specific survival rates to those of SLR. Considering that RFA

207 does not lead to any loss of pulmonary function and that it can be repeatedly performed, if a patient

208 has a tumor recurrence or a new tumor growth, it also has the following advantages: it is well

209 tolerated by outpatients and is complementary to chemotherapy, used to treat metachronous and

210 synchronous lesions, results in rapid recovery of physical performance, and has a relatively short

211 treatment time (Cheng et al. 2016; Chua et al. 2010; Li et al. 2013; Ridge et al. 2014). The four

212 complications documented in the articles we included were hemoptysis, pneumothorax, pleural

213 effusion, and cardiac abnormality. The most common complication was pneumothorax: it was

214 observed in every article and more notably in the RFA group than in the SLR group (Figure 2).

215 Although the RFA group had more complications than the SLR group, they were relatively minor.

216 However, the following disadvantage is notably observed in RFA: the application of RFA is

217 limited considering the proximity of a vascular structure to the location and size of the tumor. The

energy generated to the tumor will be reduced if there is a vessel with diameter greater than 0.3

219

$\mathrm{cm}$, owing to the loss of energy through convection within the surrounding circulatory system

(Lencioni et al. 2004). The proximity of the tumor to the trachea, heart, and esophagus increases

the risk when performing RFA. Heat is also reduced if the tumor is greater than $3 \mathrm{~cm}$ in diameter

considering its periphery; hence, it is difficult to reach an ideal ablative temperature, resulting in

an impaired local control and diminished response(Sharma et al. 2012). The advantage of SLR is

that it has better oncologic outcomes than RFA. According to Keenan's research (Keenan et al. 
226

228

229

230

231

232

233

234

235

236

237

238

239

240

241

242

243

244

245

246

lung function than does lobectomy and the forced vital capacity and forced expiratory volume in 1 second are better preserved in the SLR group than those in the RFA group. Moreover, Kodama's (Kodama et al. 1997) and Kates's (Kates et al. 2011) studies both reveal that for T1N0 NSCLC, the survival rate of SLR is also similar to that of lobectomy.

Recently, several authors reported different VATS techniques to localize lung tumors, avoiding the necessity of open thoracotomy, which can be performed through minimally invasive videoassisted thoracoscopic surgery (Ambrogi et al. 2012; Gruber-Rouh et al. 2017; Lin et al. 2016; Refai et al. 2020). Furthermore, an incidence rate of 5\% of lymph node involvement was observed in 100 NSCLC patients with tumor $<1 \mathrm{~cm}$ in diameter, suggesting that nodal assessment should be taken into consideration even in small lesions (El-Sherif et al. 2005). Hence, an additional advantage of SLR is that lymph node sampling can be performed at the time of surgical resection, allowing the identification of potential metastatic nodes and more precise staging to guide treatment. The main disadvantage of surgery is that not every patient can tolerate resection secondary to comorbid disease or poor reserve. Additionally, the SLR significantly requires a longer post-procedure length of stay and higher cost than RFA (Alexander et al. 2013).

Kim believed that RFA has a survival rate similar to that of surgical treatment in stage I NSCLC patients, specifically in those not eligible for surgical treatment (Kim et al. 2012). To confirm this hypothesis, all the clinical stage II-III NSCLC were excluded, considering that surgery is the standard treatment for these patients. Hence, our study differs from previous meta-analyses and studies, as all the included patients had stage I NSCLC, which is undoubtedly considered as earlystage NSCLC. We also considered other factors that influence patient outcomes, such as age, tumor 
247 size, and clinical condition. The SFR group patients are significantly older than the SLR group 248 patients; however, the other baseline characteristics are similar between the two groups (Table 1).

249 Moreover, according to our study, higher local recurrence is observed in the RFA group than in 250 the SLR group, and longer survival and progression-free intervals are more frequently observed in 251 the SLR group than in the RFA group. The possible reason for these hypotheses might be the existing inherent selection bias related to the neoplasm operability being defined by surgical intervention, which results in a decision algorithm stating that RFA is only to be performed after ruling out surgery. This possible reason was confirmed by a study conducted in Massachusetts General Hospital (Lanuti et al. 2009) in 2009, reporting of a group of 31 patients treated with RFA who were deemed "not eligible" for surgery. In this study, only three patients died of disseminated lung cancer. In all these four studies, the age of the participants in the RFA group was greater than that of the participants in the SLR group (Table 1), supporting the hypothesis that elderly patients are at higher risk of death, due to comorbidities, rather than lung cancer, as reflected in the RFA group in Alexander's study (Alexander et al. 2013). Moreover, the assessment of stages was more accurate for the SLR group than for the RFA group. Thus, the RFA group may be understated, resulting in survival bias. Finally, incomplete tumor ablation may also affect the survival rate. the clinical results of patients with stage I NSCLC. We compared the survival rates of SLR with those of CT-guided thermal ablation in four studies. RFA, despite its higher disease recurrence and lower survival rate, can be considered a valid alternative for inoperable and high-risk patients due to its short hospital stay and low invasiveness. 

and SLR have not been conducted. Most available studies are single-institution case series and small observational studies. Second, due to the retrospective design of the included studies,

patients undergoing RFA were older and had higher co-morbidity scores and lower performance

than patients undergoing SLR; hence, those undergoing RFA were categorically likely to die

sooner considering that they were not eligible for surgery. Although all the included studies

focused on stage I NSCLC, the different stages of NSCLC also influence the patients' survival and

local recurrence. Third, the included studies exclusively focused on stage I NSCLC. It is known

that the therapeutic effect of RFA is also closely associated with tumor size, but studies assessing

the association between RFA and tumor size have not been conducted to date. Finally, the

mediastinal and hilar lymph nodes are evaluated by preoperative imaging and not by pathologic

verification when RFA is performed. Hence, the real staging status of the patients may be

underestimated, resulting in survival bias. Moreover, with RFA, the tumor is not eliminated, and

a residual scar, which is commonly noted after treatment, can be mistaken for a recrudescent lesion.

The inclusion of additional RCTs to the studies we evaluated would have increased the significance of our results.

284

285

286

\section{Conclusion}

The outcomes of our study affirm that surgical intervention, even if just limited to SLR, has a better survival rate than RFA; therefore, it should be the preferred choice of treatment in patients, excluding those not eligible for surgery. Future large-scale prospective randomized studies would help compare the survival rates of the different approaches and define better the participants 
289

290

291

292

293

294

295

296

297

298

299

300

301

302

303

304

305

306

307

308

309

considered in the high risk group.

\section{Acknowledgments}

None.

\section{Funding}

This research was supported by a grant (NO. 81702242) from the National Science Foundation of China.

\section{References:}

Alexander ES, Machan JT, Ng T, Breen LD, DiPetrillo TA, and Dupuy DE. 2013. Cost and effectiveness of radiofrequency ablation versus limited surgical resection for stage I non-small-cell lung cancer in elderly patients: is less more? J Vasc Interv Radiol 24:476-482. 10.1016/j.jvir.2012.12.016

Ambrogi MC, Fanucchi O, Cioni R, Dini P, De Liperi A, Cappelli C, Davini F, Bartolozzi C, and Mussi A. 2011. Long-term results of radiofrequency ablation treatment of stage I non-small cell lung cancer: a prospective intention-to-treat study. J Thorac Oncol 6:2044-2051. 10.1097/JTO.0b013e31822d538d

Ambrogi MC, Fanucchi O, Dini P, Melfi F, Davini F, Lucchi M, Massimetti G, and Mussi A. 2015. Wedge resection and radiofrequency ablation for stage I nonsmall cell lung cancer. Eur Respir $J$ 45:1089-1097. $10.1183 / 09031936.00188014$

Ambrogi MC, Melfi F, Zirafa C, Lucchi M, De Liperi A, Mariani G, Fanucchi O, and Mussi A. 2012. Radio-guided thoracoscopic surgery (RGTS) of small pulmonary nodules. Surg Endosc 26:914-919. 10.1007/s00464-0111967-8

Chang JY, Senan S, Paul MA, Mehran RJ, Louie AV, Balter P, Groen HJ, McRae SE, Widder J, Feng L, van den Borne BE, Munsell MF, Hurkmans C, Berry DA, van Werkhoven E, Kresl JJ, Dingemans AM, Dawood O, 
ablative radiotherapy versus lobectomy for operable stage I non-small-cell lung cancer: a pooled analysis of two randomised trials. Lancet Oncol 16:630-637. 10.1016/s1470-2045(15)70168-3

Dong S, Du J, Li W, Zhang S, Zhong X, and Zhang L. 2015. Systematic mediastinal lymphadenectomy or mediastinal lymph node sampling in patients with pathological stage I NSCLC: a meta-analysis. World J Surg 39:410416. $10.1007 / \mathrm{s} 00268-014-2804-8$

Dong S, Zhang L, Li W, Du J, Liu X, and Chen X. 2014. Evaluation of video-assisted thoracoscopic surgery for pulmonary metastases: a meta-analysis. PLoS One 9:e85329. 10.1371/journal.pone.0085329

Donington J, Ferguson M, Mazzone P, Handy J, Jr., Schuchert M, Fernando H, Loo B, Jr., Lanuti M, de Hoyos A, Detterbeck F, Pennathur A, Howington J, Landreneau R, and Silvestri G. 2012. American College of Chest Physicians and Society of Thoracic Surgeons consensus statement for evaluation and management for highrisk patients with stage I non-small cell lung cancer. Chest 142:1620-1635. 10.1378/chest.12-0790 
331 Downs SH, and Black N. 1998. The feasibility of creating a checklist for the assessment of the methodological quality

332

333

334

335

336 both of randomised and non-randomised studies of health care interventions. J Epidemiol Community Health 52:377-384. 10.1136/jech.52.6.377

El-Sherif A, Luketich JD, Landreneau RJ, and Fernando HC. 2005. New therapeutic approaches for early stage nonsmall cell lung cancer. Surg Oncol 14:27-32. 10.1016/j.suronc.2004.11.002

Fernando HC, Hoyos AD, Litle V, Belani CP, and Luketich JD. 2004. Radiofrequency ablation: identification of the ideal patient. Clin Lung Cancer 6:149-153. 10.3816/clc.2004.n.027

Ginsberg RJ, and Rubinstein LV. 1995. Randomized trial of lobectomy versus limited resection for T1 N0 non-small cell lung cancer. Lung Cancer Study Group. Ann Thorac Surg 60:615-622; discussion 622-613. $10.1016 / 0003-4975(95) 00537-u$

Grills IS, Mangona VS, Welsh R, Chmielewski G, McInerney E, Martin S, Wloch J, Ye H, and Kestin LL. 2010. Outcomes after stereotactic lung radiotherapy or wedge resection for stage I non-small-cell lung cancer. $J$ Clin Oncol 28:928-935. 10.1200/jco.2009.25.0928

Gruber-Rouh T, Naguib NNN, Beeres M, Kleine P, Vogl TJ, Jacobi V, Alsubhi M, and Nour-Eldin NA. 2017. CTguided hook-wire localisation prior to video-assisted thoracoscopic surgery of pulmonary lesions. Clin Radiol 72:898.e897-898.e811. 10.1016/j.crad.2017.05.015

Harada H, Okada M, Sakamoto T, Matsuoka H, and Tsubota N. 2005. Functional advantage after radical segmentectomy versus lobectomy for lung cancer. Ann Thorac Surg 80:2041-2045. 10.1016/j.athoracsur.2005.06.010

Hiraki T, Gobara H, Iguchi T, Fujiwara H, Matsui Y, and Kanazawa S. 2014. Radiofrequency Ablation for EarlyStage Nonsmall Cell Lung Cancer. Biomed Res Int 2014. 10.1155/2014/152087

Peer] reviewing PDF | (2020:01:45114:2:0:NEW 25 Apr 2020) 
352 Howington JA, Blum MG, Chang AC, Balekian AA, and Murthy SC. 2013. Treatment of stage I and II non-small cell

353

354

355

356

357

358

359

360

361

362

363

364

365

366

367

368

369

370

371

372 lung cancer: Diagnosis and management of lung cancer, 3rd ed: American College of Chest Physicians

evidence-based clinical practice guidelines. Chest 143:e278S-e313S. 10.1378/chest.12-2359

Jones GC, Kehrer JD, Kahn J, Koneru BN, Narayan R, Thomas TO, Camphausen K, Mehta MP, and Kaushal A. 2015. Primary Treatment Options for High-Risk/Medically Inoperable Early Stage NSCLC Patients. Clin Lung Cancer 16:413-430. 10.1016/j.cllc.2015.04.001

Kates M, Swanson S, and Wisnivesky JP. 2011. Survival following lobectomy and limited resection for the treatment of stage I non-small cell lung cancer $<=1 \mathrm{~cm}$ in size: a review of SEER data. Chest 139:491-496. 10.1378/chest.09-2547

Keenan RJ, Landreneau RJ, Maley RH, Jr., Singh D, Macherey R, Bartley S, and Santucci T. 2004. Segmental resection spares pulmonary function in patients with stage I lung cancer. Ann Thorac Surg 78:228-233; discussion 228-233. 10.1016/j.athoracsur.2004.01.024

Kim SR, Han HJ, Park SJ, Min KH, Lee MH, Chung CR, Kim MH, Jin GY, and Lee YC. 2012. Comparison between surgery and radiofrequency ablation for stage I non-small cell lung cancer. Eur $J$ Radiol 81:395-399. 10.1016/j.ejrad.2010.12.091

Kodama H, Yamakado K, Hasegawa T, Takao M, Taguchi O, Fukai I, and Sakuma H. 2014. Radiofrequency ablation for ground-glass opacity-dominant lung adenocarcinoma. $J$ Vasc Interv Radiol 25:333-339. 10.1016/j.jvir.2013.11.035

Kodama K, Doi O, Higashiyama M, and Yokouchi H. 1997. Intentional limited resection for selected patients with T1 N0 M0 non-small-cell lung cancer: a single-institution study. J Thorac Cardiovasc Surg 114:347-353. 10.1016/s0022-5223(97)70179-x

Peer) reviewing PDF | (2020:01:45114:2:0:NEW 25 Apr 2020) 
373 Lanuti M, Sharma A, Digumarthy SR, Wright CD, Donahue DM, Wain JC, Mathisen DJ, and Shepard JA. 2009.

374

375

376

377

378
Radiofrequency ablation for treatment of medically inoperable stage I non-small cell lung cancer. $J$ Thorac Cardiovasc Surg 137:160-166. 10.1016/j.jtcvs.2008.08.034

Lencioni R, Crocetti L, Cioni R, Mussi A, Fontanini G, Ambrogi M, Franchini C, Cioni D, Fanucchi O, Gemignani R, Baldassarri R, Angeletti CA, and Bartolozzi C. 2004. Radiofrequency ablation of lung malignancies: where do we stand? Cardiovasc Intervent Radiol 27:581-590. 10.1007/s00270-004-0008-6

Li X, Zhao M, Wang J, Fan W, Li W, Pan T, and Wu P. 2013. Percutaneous CT-guided radiofrequency ablation as supplemental therapy after systemic chemotherapy for selected advanced non-small cell lung cancers. $A J R$ Am J Roentgenol 201:1362-1367. 10.2214/ajr.12.10511

Liberati A, Altman DG, Tetzlaff J, Mulrow C, Gotzsche PC, Ioannidis JP, Clarke M, Devereaux PJ, Kleijnen J, and Moher D. 2009. The PRISMA statement for reporting systematic reviews and meta-analyses of studies that evaluate health care interventions: explanation and elaboration. $J$ Clin Epidemiol 62:e1-34. 10.1016/j.jclinepi.2009.06.006

Lin MW, Tseng YH, Lee YF, Hsieh MS, Ko WC, Chen JY, Hsu HH, Chang YC, and Chen JS. 2016. Computed tomography-guided patent blue vital dye localization of pulmonary nodules in uniportal thoracoscopy. $J$ Thorac Cardiovasc Surg 152:535-544.e532. 10.1016/j.jtcvs.2016.04.052

Menezes RJ, Roberts HC, Paul NS, McGregor M, Chung TB, Patsios D, Weisbrod G, Herman S, Pereira A, McGregor A, Dong Z, Sitartchouk I, Boerner S, Tsao MS, Keshavjee S, and Shepherd FA. 2010. Lung cancer screening using low-dose computed tomography in at-risk individuals: the Toronto experience. Lung Cancer 67:177-

183. 10.1016/j.lungcan.2009.03.030

Peer) reviewing PDF | (2020:01:45114:2:0:NEW 25 Apr 2020) 
393

401

402
Palussiere J, Lagarde P, Auperin A, Deschamps F, Chomy F, and de Baere T. 2015. Percutaneous lung thermal ablation of non-surgical clinical N0 non-small cell lung cancer: results of eight years' experience in 87 patients from two centers. Cardiovasc Intervent Radiol 38:160-166. 10.1007/s00270-014-0999-6

Refai M, Andolfi M, Barbisan F, Roncon A, Guiducci GM, Xiume F, Salati M, Tiberi M, Giovagnoni A, and Paci E. 2020. Computed tomography-guided microcoil placement for localizing small pulmonary nodules before uniportal video-assisted thoracoscopic resection. Radiol Med 125:24-30. 10.1007/s11547-019-01077-x

Ridge CA, Silk M, Petre EN, Erinjeri JP, Alago W, Downey RJ, Sofocleous CT, Thornton RH, and Solomon SB. 2014. Radiofrequency ablation of T1 lung carcinoma: comparison of outcomes for first primary, metachronous, and synchronous lung tumors. J Vasc Interv Radiol 25:989-996. 10.1016/j.jvir.2014.02.021

Safi S, Rauch G, op den Winkel J, Kunz J, Schneider T, Bischof M, Heussel CP, Huber PE, Herth FJ, Dienemann H, and Hoffmann H. 2015. Sublobar Resection, Radiofrequency Ablation or Radiotherapy in Stage I Non-Small Cell Lung Cancer. Respiration 89:550-557. 10.1159/000381555

Sharma A, Abtin F, and Shepard JA. 2012. Image-guided ablative therapies for lung cancer. Radiol Clin North Am 50:975-999. 10.1016/j.rcl.2012.06.004

Simon CJ, Dupuy DE, DiPetrillo TA, Safran HP, Grieco CA, Ng T, and Mayo-Smith WW. 2007. Pulmonary radiofrequency ablation: long-term safety and efficacy in 153 patients. Radiology 243:268-275. 10.1148/radiol.2431060088

Speicher PJ, Gu L, Gulack BC, Wang X, D'Amico TA, Hartwig MG, and Berry MF. 2016. Sublobar Resection for Clinical Stage IA Non-small-cell Lung Cancer in the United States. Clin Lung Cancer 17:47-55. 10.1016/j.cllc.2015.07.005 
413 Torre LA, Siegel RL, and Jemal A. 2016. Lung Cancer Statistics. Adv Exp Med Biol 893:1-19. 10.1007/978-3-31924223-1_1

415

416

417

418

419

420

421

422

423

424

425

426

427

428
Veronesi G, Bellomi M, Mulshine JL, Pelosi G, Scanagatta P, Paganelli G, Maisonneuve P, Preda L, Leo F, Bertolotti R, Solli P, and Spaggiari L. 2008. Lung cancer screening with low-dose computed tomography: a noninvasive diagnostic protocol for baseline lung nodules. Lung Cancer 61:340-349. 10.1016/j.lungcan.2008.01.001

Wan J, Wu W, Huang Y, Ge W, and Liu S. 2016a. Incomplete radiofrequency ablation accelerates proliferation and angiogenesis of residual lung carcinomas via HSP70/HIF-1alpha. Oncol Rep 36:659-668. $10.3892 /$ or. 2016.4858

Wan J, Wu W, and Zhang R. 2016b. Local recurrence of small cell lung cancer following radiofrequency ablation is induced by HIF-1alpha expression in the transition zone. Oncol Rep 35:1297-1308. 10.3892/or.2015.4541

Zemlyak A, Moore WH, and Bilfinger TV. 2010. Comparison of survival after sublobar resections and ablative therapies for stage I non-small cell lung cancer. $J$ Am Coll Surg 211:68-72. 10.1016/j.jamcollsurg.2010.03.020 


\section{Figure legends}

430 Figure 1. Flow chart of the inclusion criteria of the present research.

431 Figure 2. Hemoptysis(a), pneumothorax(b), pleural effusion(c) and cardiac abnormality(d) forest 432 plot of the odds ratio (OR), following SLR versus RFA for stage I NSCLC.

433 Figure 3. One-(a) and three-year(b) survival rate forest plot of the odds ratio (OR), following SLR 434 versus RFA for stage I NSCLC.

435 Figure 4. One-(a) and three-year(b) progression-free survival rate and local recurrence (c) forest 436 plot of the odds ratio (OR), following SLR versus RFA for stage I NSCLC.

Figure 5. Funnel plot of the outcome of one-year survival rate. 
Figure 1

Flow chart of the identification of researches for inclusion.

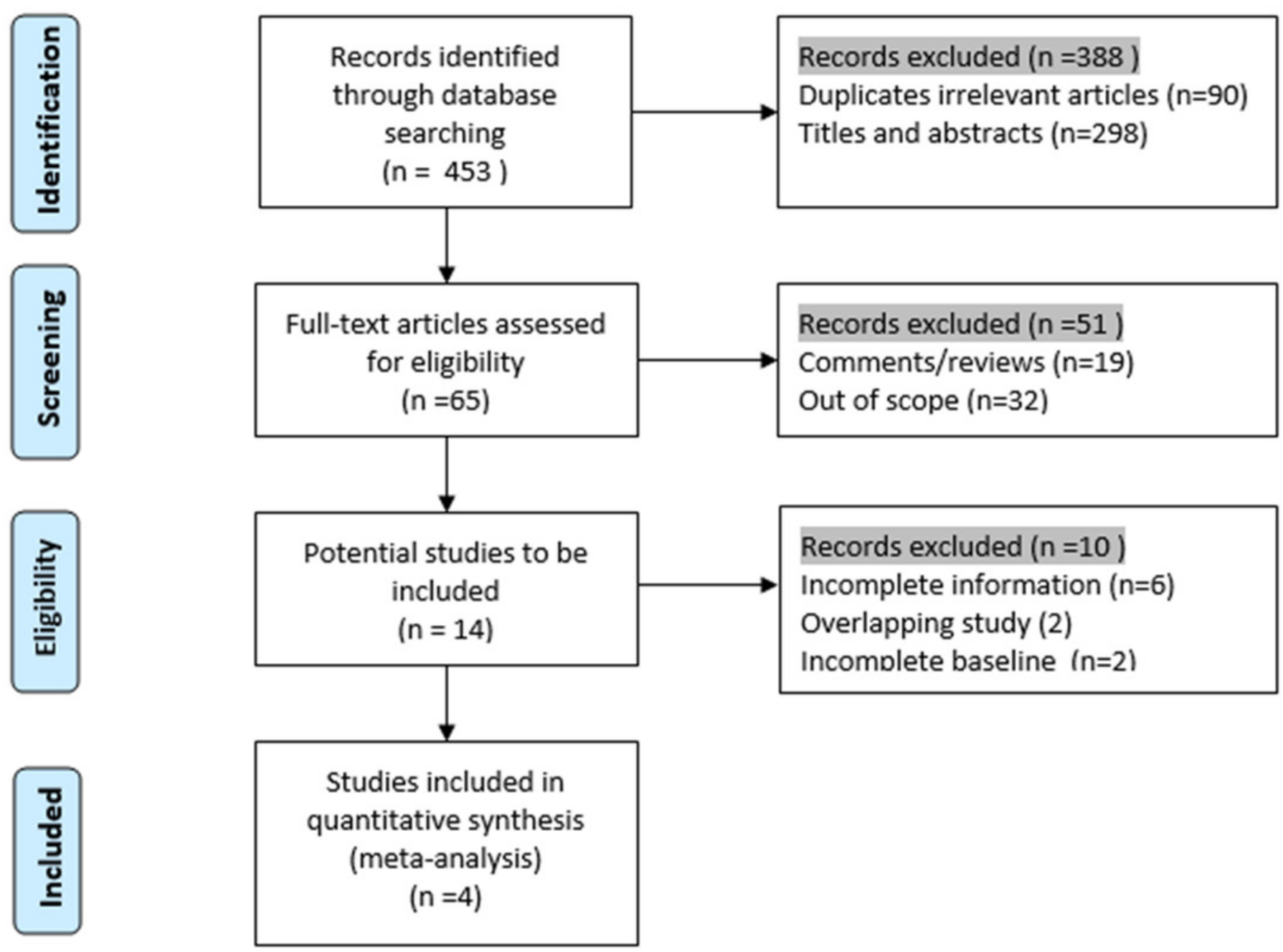


Figure 2

Hemoptysis(a), pneumothorax(b), pleural effusion(c) and cardiac abnormality(d) forest plot of the Odds Ratio(OR) following SLR versus RFA for stage I NSCLC.

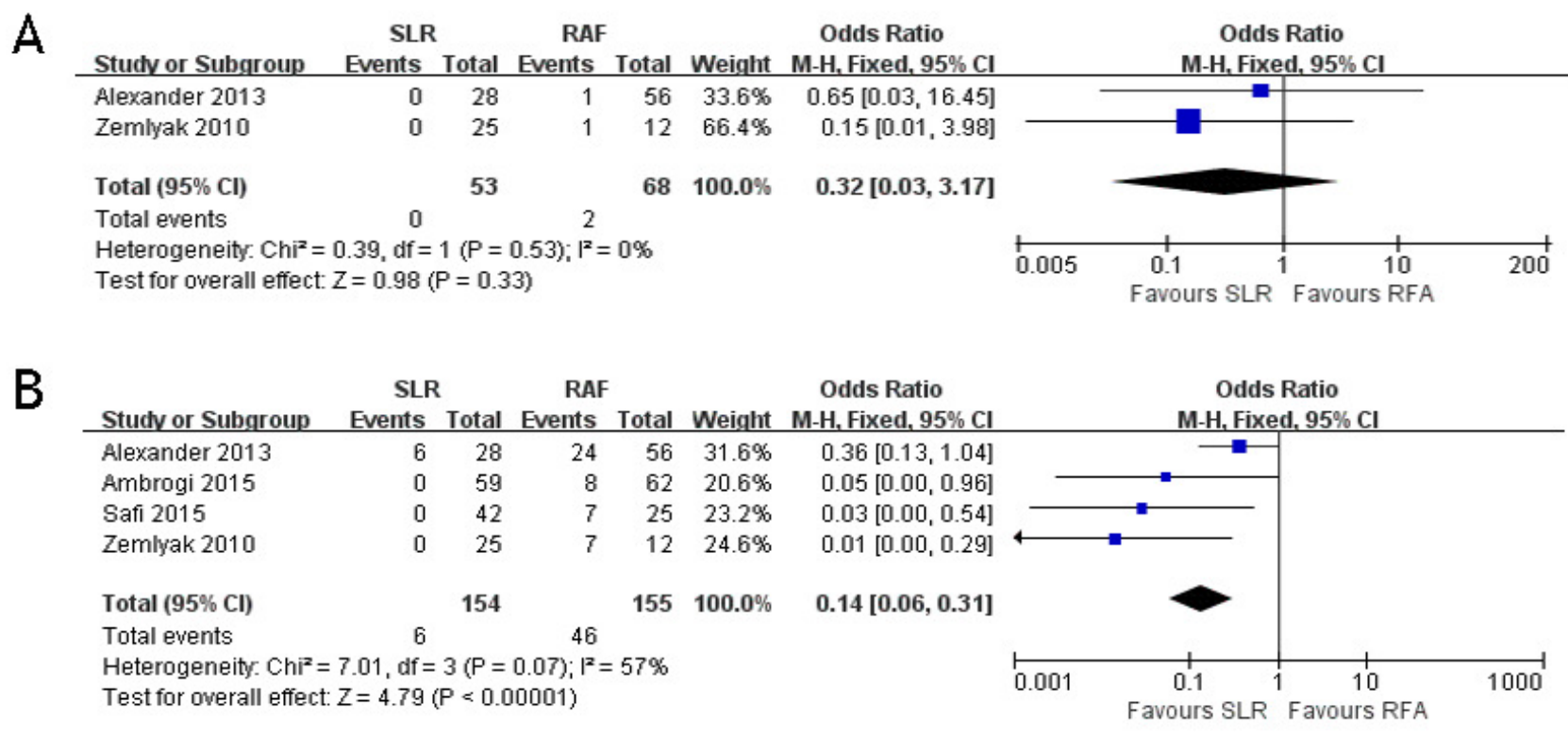
C

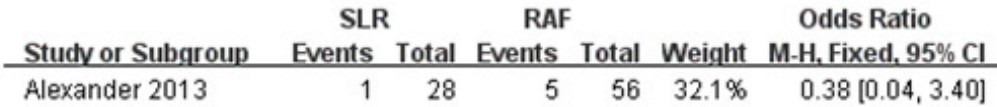 Ambrogi 2015 Safi 2015

$\begin{array}{ll}0 & 59 \\ 1 & 42\end{array}$

$4 \quad 62 \quad 43.5 \%$
Total $(95 \% \mathrm{Cl})$

129
$225 \quad 24.4 \%$
$0.11[0.01,2.07]$
$0.28[0.02,3.26]$
Total events 2

129
Heterogeneity: $\mathrm{Chi}^{2}=0.46, \mathrm{df}=2(P=0.80) ; \mathrm{I}^{2}=0 \%$
Test for overall effect: $Z=1.99(P=0.05)$

\section{$143 \quad 100.0 \% \quad 0.24[0.06,0.98]$} 11

RAF

SLR RAF

Odds Ratio

Study or Subgroup Events Total Events Total Weight M-H, Fixed, 95\% Cl Alexander 2013 Ambrogi 2015 Safi 2015

$\begin{array}{rrrrrr}6 & 28 & 0 & 56 & 20.5 \% & 32.64[1.76,603.84] \\ 5 & 59 & 0 & 62 & 34.7 \% & 12.61[0.68,233.37] \\ 3 & 42 & 0 & 25 & 44.8 \% & 4.52[0.22,91.20]\end{array}$

Total $(95 \% \mathrm{Cl})$

Total events $14 \quad 129 \quad 0$

$143100.0 \%$

Heterogeneity: $\mathrm{Chi}^{2}=0.86, \mathrm{df}=2(\mathrm{P}=0.65) ; \mathrm{I}^{2}=0 \%$

Test for overall effect: $Z=3.01(P=0.003)$

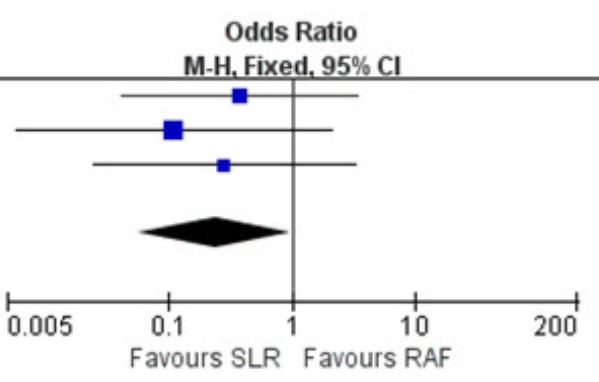




\section{Figure 3}

\section{One-(a) and three-year(b) survival rate Forest plot of the Odds Ratio (OR) following SLR versus RFA for stage I NSCLC.}

A

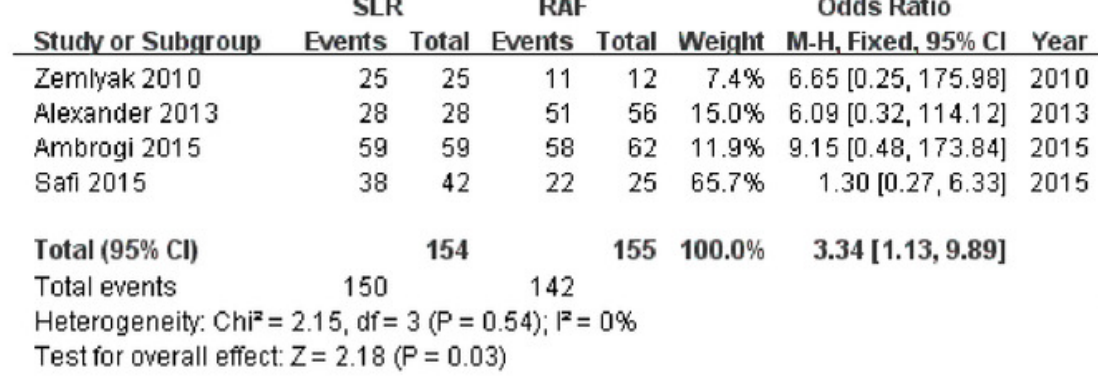

Heterogeneity: $\mathrm{Chi}^{2}=2.15, \mathrm{df}=3(\mathrm{P}=0.54) ; \mathrm{I}^{2}=0 \%$

B

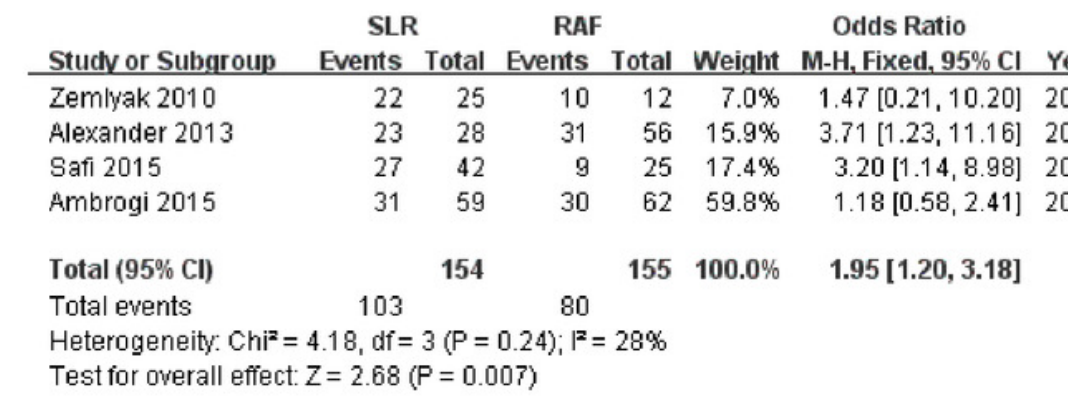

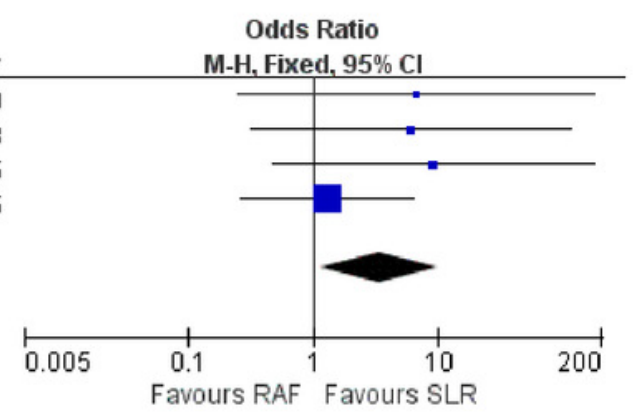

Odds Ratio M-H, Fixed, 95\%

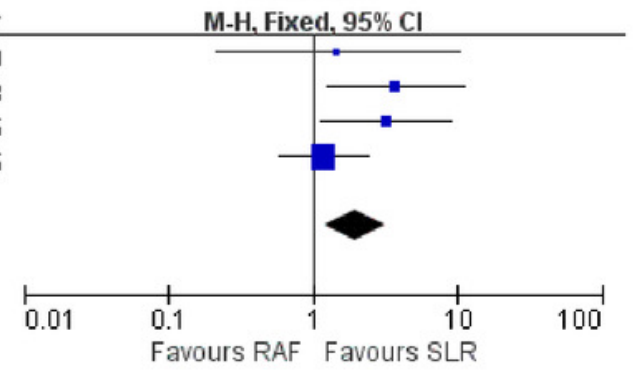




\section{Figure 4}

\section{One-(a) and three-year(b) progression-free survival rate and local recurrence (c) forest plot of the Odds Ratio (OR) following SLR versus RFA for stage I NSCLC.}

\begin{tabular}{|c|c|c|c|c|c|c|c|c|c|c|c|c|}
\hline \multirow[t]{7}{*}{ A } & Study or Subgroup & \multicolumn{2}{|c|}{ SLR } & $\begin{array}{l}\text { RAF } \\
\text { Events }\end{array}$ & Total & Weight & $\begin{array}{c}\text { Odds Ratio } \\
\text { M-H, Fixed, } 95 \% \mathrm{Cl}\end{array}$ & Year & \multicolumn{4}{|c|}{$\begin{array}{c}\text { Odds Ratio } \\
\text { M-H, Fixed, 95\% Cl } \\
\end{array}$} \\
\hline & Zemlyak 2010 & 25 & 25 & 11 & 12 & $4.3 \%$ & $6.65[0.25,175.98]$ & 2010 & & & & \\
\hline & Ambrogi 2015 & 34 & 42 & 16 & 25 & $56.2 \%$ & $2.39[0.78,7.35]$ & 2015 & & & & \\
\hline & Safi 2015 & 56 & 59 & 54 & 62 & $39.4 \%$ & $2.77[0.70,10.98]$ & 2015 & & & & \\
\hline & Total $(95 \% \mathrm{Cl})$ & & 126 & & 99 & $100.0 \%$ & $2.72[1.18,6.29]$ & & & & & \\
\hline & Total events & 115 & & 81 & & & & & & & & \\
\hline & $\begin{array}{l}\text { Heterogeneity: } \mathrm{Chi}^{2}= \\
\text { Test for owerall effect }\end{array}$ & $\begin{array}{l}0.34, d f= \\
Z=2.35\end{array}$ & $\begin{array}{l}2(P=1 \\
P=0.0\end{array}$ & $\begin{array}{l}0.84) ; 1^{2}= \\
12)\end{array}$ & $0 \%$ & & & & 0.01 & $\begin{array}{l}0.1 \\
\text { Favours RAF }\end{array}$ & $1 \quad 10$ & 100 \\
\hline B & Studv or Subgroup & $\begin{array}{l}\text { SLR } \\
\text { Events }\end{array}$ & Total & $\begin{array}{l}\text { RAF } \\
\text { Events }\end{array}$ & Total & Weight & $\begin{array}{c}\text { Odds Ratio } \\
\text { M-H, Fixed, } 95 \% \mathrm{Cl}\end{array}$ & Year & & $\begin{array}{r}\text { Odds I } \\
\text { M-H, Fixe }\end{array}$ & $\begin{array}{l}\text { Ratio } \\
\text { d, } 95 \% \mathrm{Cl}\end{array}$ & \\
\hline & Zemlyak 2010 & 15 & 25 & 6 & 12 & $26.4 \%$ & $1.50[0.38,6.00]$ & 2010 & & & $=$ & \\
\hline & Safi 2015 & 18 & 42 & 6 & 25 & $34.9 \%$ & $2.38[0.79,7.15]$ & 2015 & & & & \\
\hline & Ambrogi 2015 & 51 & 59 & 36 & 62 & $38.7 \%$ & $4.60[1.87,11.32]$ & 2015 & & & & \\
\hline & Total $(95 \% \mathrm{Cl})$ & & 126 & & 99 & $100.0 \%$ & $3.01[1.63,5.55]$ & & & & & \\
\hline & Total events & 84 & & 48 & & & & & & & & \\
\hline & $\begin{array}{l}\text { Heterogeneity: } \mathrm{Ch}^{2}= \\
\text { Test for averall effect: }\end{array}$ & $\begin{array}{l}2.00, d f= \\
Z=3.52(f\end{array}$ & $\begin{array}{l}2(P=0 \\
P=0.00\end{array}$ & $\begin{array}{l}0.37) ; F^{2}= \\
004)\end{array}$ & $0 \%$ & & & & 0.01 & $\begin{array}{l}0.1 \\
\text { Favours RAF }\end{array}$ & $\begin{array}{l}1 \\
\text { Favours SLR }\end{array}$ & 100 \\
\hline C & Studv or Subgroup & $\begin{array}{c}\text { SLR } \\
\text { Events }\end{array}$ & Total & $\begin{array}{l}\text { RAF } \\
\text { Events }\end{array}$ & Total & Weight & $\begin{array}{c}\text { Odds Ratio } \\
\mathrm{M}-\mathrm{H}, \text { Fixed, } 95 \% \mathrm{Cl}\end{array}$ & Year & & $\begin{array}{r}\text { Odds } \\
\text { M-H, Fixe }\end{array}$ & $\begin{array}{l}\text { Ratio } \\
\text { d, } 95 \% \mathrm{Cl}\end{array}$ & \\
\hline & Zemlyak 2010 & 3 & 25 & 4 & 12 & $10.2 \%$ & $0.27[0.05,1.50]$ & 2010 & & & + & \\
\hline & Alexander 2013 & $?$ & 28 & 28 & 56 & $30.1 \%$ & $0.33[0.12,0.91]$ & 2013 & & & & \\
\hline & Ambrogi 2015 & 1 & 59 & 14 & 62 & $28.8 \%$ & $0.06[0.01,0.47]$ & 2015 & & & & \\
\hline & Safi 2015 & 5 & 42 & 13 & 25 & $30.9 \%$ & $0.12[0.04,0.42]$ & 2015 & & & & \\
\hline & Total (95\% Cl) & & 154 & & 155 & $100.0 \%$ & $0.18[0.10,0.35]$ & & & & & \\
\hline & Total events & $\begin{array}{c}16 \\
11\end{array}$ & & 59 & & & & & & & & \\
\hline & $\begin{array}{l}\text { Heterogeneity: } \mathrm{Ch}^{\mathbf{2}}= \\
\text { Test for averall effect }\end{array}$ & $\begin{array}{l}3.11, d f= \\
Z=5.08 \text { (F }\end{array}$ & $\begin{array}{l}3(P=0 \\
P<0.00\end{array}$ & $\begin{array}{l}0.38) ; F^{2}= \\
0001)\end{array}$ & $3 \%$ & & & & 0.01 & ${ }_{\text {Favours SLR }}^{0.1}$ & $1 \frac{10}{\text { Favours RAF }}$ & 100 \\
\hline
\end{tabular}


Figure 5

Funnel plot of the outcome of one-year survival rate.

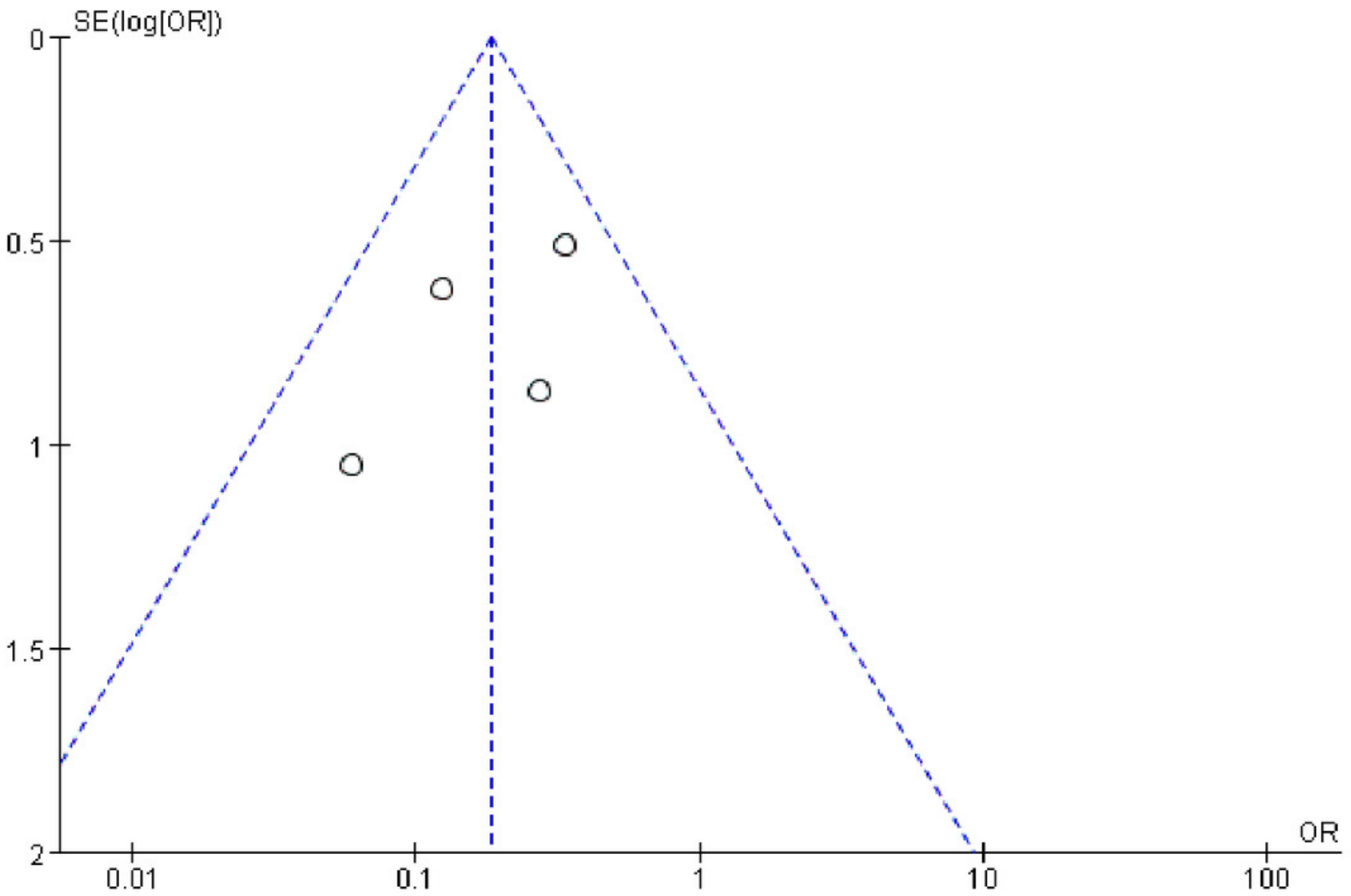




\section{Table $\mathbf{1}$ (on next page)}

The evaluation index and characteristics of the included researches. 
Table 1 The evaluation index and characteristics of the included researches.

2

\begin{tabular}{|c|c|c|c|c|c|c|c|c|c|}
\hline Study & Design & Country & $\mathrm{NO}$ & Gender (M/F) & $\begin{array}{c}\text { Mean age } \\
\text { (years) }\end{array}$ & $\begin{array}{l}\text { Tumor size } \\
(\mathrm{mm})\end{array}$ & $\begin{array}{l}\text { FEV1/ } \\
\text { Predicted(\%) }\end{array}$ & $\begin{array}{l}\text { Hospital } \\
\text { stay(Day) }\end{array}$ & $\begin{array}{l}\text { Assessme } \\
\text { score }\end{array}$ \\
\hline \multirow{2}{*}{$\begin{array}{l}\text { Zemlyak } \\
\text { (Zemlyak } \\
\text { et al. 2010) }\end{array}$} & \multirow{2}{*}{$\mathrm{OC}$} & \multirow{2}{*}{ USA } & S 25 & S 9/16 & S 66.0 & $\mathrm{NR}$ & S 65 & 6 & \multirow{2}{*}{14} \\
\hline & & & R 12 & $\mathrm{R} 7 / 5$ & R 74.0 & NR & R 64 & 1.8 & \\
\hline \multirow{2}{*}{$\begin{array}{l}\text { Alexander } \\
\text { (Alexander } \\
\text { et al. 2013) }\end{array}$} & \multirow{2}{*}{$\mathrm{OC}$} & \multirow{2}{*}{ USA } & S 28 & S 12/16 & S 73.8 & NR & S 54 & 5 & \multirow{2}{*}{18} \\
\hline & & & R 56 & R 24/32 & R 77.6 & NR & R 52 & 0 & \\
\hline \multirow{2}{*}{$\begin{array}{l}\text { Ambrogi } \\
\text { (Ambrogi } \\
\text { et al. 2015) }\end{array}$} & \multirow{2}{*}{$\mathrm{OC}$} & \multirow{2}{*}{ Italy } & S 59 & S $46 / 13$ & S 70.0 & 26 & S 47 & 6 & \multirow{2}{*}{19} \\
\hline & & & R 62 & $\mathrm{R} 45 / 17$ & R 76.0 & 23 & R 49 & 2 & \\
\hline \multirow{2}{*}{$\begin{array}{l}\text { Safi } \\
\text { (Safi } \\
\text { et al. 2015) }\end{array}$} & \multirow{2}{*}{$\mathrm{OC}$} & \multirow{2}{*}{ Germany } & S 42 & S $27 / 15$ & S 69.6 & 19 & S 69 & NR & \multirow{2}{*}{15} \\
\hline & & & R 25 & R 34/15 & R 71.2 & 22 & R 67 & NR & \\
\hline
\end{tabular}

S SLR, R RFA, M Male, F Female, OC Observational cohort, NR Not reported 


\section{Table 2 (on next page)}

Summary of the outcomes between SLR and RFA of patients with stage I NSCLC. 
1 Table 2. Summary of the outcomes between SLR and RFA of patients with stage I NSCLC.

\begin{tabular}{|c|c|c|c|c|c|}
\hline \multirow[t]{2}{*}{ Variables } & \multicolumn{2}{|c|}{ Results } & \multirow[t]{2}{*}{ OR } & \multirow[t]{2}{*}{$P$-value } & \multirow[t]{2}{*}{$I^{2}$} \\
\hline & SLR & RFA & & & \\
\hline 1-y survival & $97 \%$ & $91 \%$ & 3.34 & 0.03 & $0 \%$ \\
\hline 3-y survival & $67 \%$ & $52 \%$ & 1.95 & 0.007 & $28 \%$ \\
\hline 1-y progression-free survival & $91 \%$ & $81 \%$ & 2.72 & 0.02 & $0 \%$ \\
\hline 3- y progression-free survival & $67 \%$ & $48 \%$ & 3.01 & 0.0004 & $0 \%$ \\
\hline
\end{tabular}

2 